\title{
IDENTIDADE CULTURAL NA PÓS-MODERNIDADE E A RELIGIOSIDADE DOS ASSISTENTES SOCIAIS
}

\section{Cultural Identity in the Post Modernity and Religiosity of Social Workers}

\author{
Patrícia Vicente Dutra ${ }^{1}$ \\ Claudia Neves da Silva ${ }^{2}$
}

\begin{abstract}
Resumo: O presente texto busca, de forma sucinta, tratar sobre os aspectos relacionados à compreensão do fenômeno religioso no interior do Serviço Social brasileiro, especificamente sobre a religiosidade de assistentes sociais, tendo como ponto de partida os estudos de Stuart Hall sobre identidade e pós-modernidade, além das demais referências obtidas com a pesquisa sobre o tema. Será possível observar que, obviamente de forma não exclusiva, partícipes de uma sociedade que emprega entre suas características a dificuldade de seus indivíduos em construir e estabelecer de forma clara sua própria identidade, os profissionais de Serviço Social apresentam suas identificações religiosas e por vezes utilizam de sua fé como um recurso à prática profissional.
\end{abstract}

Palavras-Chaves: Serviço Social; identidade; religião; pós-modernidade.

Abstract: This paper seeks, briefly, to deal with aspects related to the understanding of the religious phenomenon within the Brazilian Social Work, specifically about the religiosity of social workers, starting with Stuart Hall's studies on identity and post -modernity, in addition to the other references obtained from research on the subject. It will be observed that obviously non-exclusively participants in a society that employs among its characteristics the difficulty of its individuals to clearly build and establish their own identity, Social Work professionals present their religious identifications and sometimes use your faith as a resource for professional practice.

Keywords: Social Work; identity; religion; postmodernity.

\footnotetext{
${ }^{1}$ Assistente Social da Defensoria Pública do Estado do Paraná. Mestre em Serviço Social pela Universidade do Oeste do Paraná. Estudante de doutorado do Programa de Pós-Graduação em Serviço Social e Política Social/UEL.

${ }^{2}$ Doutora em História (UNESP - Assis/SP). Professora Associada do Departamento de Serviço Social e do Programa de Pós-Graduação em Política Social e Serviço Social da Universidade Estadual de Londrina/UEL. Membro do Laboratório de Estudos sobre as Religiões e Religiosidades.
} 


\section{INTRODUÇÃO}

Objetiva-se com estas linhas tratar brevemente sobre o tema proposto, uma vez que se compreende que a identidade cultural na pós-modernidade é um dos elementos capazes de aprofundar os estudos sobre os questionamentos entre a relação do trabalho do Assistente Social e a religião e/ou prática religiosa. Este texto trata-se de uma breve revisão de literatura sobre o tema mais abrangente, cultura e contemporaneidade, com títulos que contribuem para a nossa compreensão sobre modernidade, pós-modernidade, cultura e identidade. É válido mencionar que o trabalho aqui apresentado é parte aprofundada dos estudos apresentados no Seminário Internacional de Práticas Religiosas no Mundo Contemporâneo, ocorrido entre os dias 8 e 10 de abril de 2019 na Universidade Estadual de Londrina ${ }^{3}$.

De acordo com Stuart Hall (2006), a temática da identidade - que para o autor se desvela introdutoriamente em três concepções, que seriam o sujeito do iluminismo, o sociológico e o pós-moderno - vem sendo ampla e extensivamente discutida em nossa sociedade; e isso se deve ao fato de que a identidade do sujeito que vive em sociedade, a identidade do ser humano, já não pode mais ser compreendida como algo estável, fixo e único. Para o autor, somos espectadores de um declínio da estabilidade do mundo social.

O sujeito moderno parece ser aquele fragmentado, expectador de inúmeras possibilidades e definições para a construção de sua própria identidade, daí um sujeito com "crise de identidade". Talvez essa crise possa ser compreendida, pelo menos em partes, pelo “abismo de sentido" (TASCHNER, 2009, p. 34) característica do período pós-moderno. A crise do sujeito talvez seja resultado, entre demais coisas, pelo processo de "destruição dos significados", presente na pós-modernidade.

A identidade ganhou o lugar e destaque na discussão porque justamente está em crise. Como é possível estabelecer quem e o que somos, de onde viemos, para onde vamos, por quais motivos e meios, em uma sociedade que não parece mais estar ancorada em um órgão central de quaisquer movimentos reais ou figurados? De acordo com Scarlatelli et. al. (2006, p. 7),

A terra parece que se tornou pequena para a humanidade. Não tanto pela falta de capacidade de acolher o crescente número de seres humanos, nem pela limitação ou escassez de recursos físicos de sobrevivência. A terra tornou-se pequena devido à forma ou às formas que nós, humanos, fomos criando e

\footnotetext{
${ }^{3}$ http://www.uel.br/laboratorios/religiosidade/anais/index.php/viii2019/viii2019/schedConf/presentations
} 
organizando para viver. Vivemos tempos de aguda perplexidade em que somos provocados a aplicar um olhar ao mesmo tempo compassivo e interrogador para compreender de onde viemos, onde estamos e aonde vamos.

Os assistentes sociais brasileiros vivenciam estes questionamentos todo o tempo em seu cotidiano de trabalho, em que lidam diretamente com as mais diversas expressões da questão social. Quais respostas dar para tantas perguntas? Quais recursos selecionar para tal? Se então a sociedade parece já não estar mais ancorada em um órgão central, como se supunha, se não há mais um ponto fixo, se não há mais o oferecimento de coerência e estabilidade, a experiência social desloca-se para o campo da dúvida e da incerteza, de modo que a identidade entre em crise. (HALL, 2006).

O conflito estaria na dificuldade do ser humano em dar resposta ao questionamento sobre si próprio, sobre quem é. As diversas possibilidades que a sociedade moderna coloca diante do ser humano, a ampliação de escolhas, a ampliação, por exemplo, em uma sociedade de consumo, da gama de produtos dispostos no mercado à escolha do consumidor gera uma insegurança e isso leva o ser humano a buscar uma sustentação, um norte, uma referência que traga sentido às suas escolhas e uma referência de vida.

É justamente nesta busca de norte e referência que a religião - aqui nos limitaremos à religião cristã - cumpre um papel importante, uma vez que estabelece normas e regras de convivência, tem grupos aparentemente definidos e é imbuída de uma imagem de tradição. No entanto, não podemos deixar de refletir que mesmo a religião se torna questionável, porque precisa de mecanismos para dar respostas e também se fragmenta, apresentando-se em várias opções para seus seguidores e fiéis.

Para Martelli, a pós-modernidade representa o fim da história e também o fim do sujeito, daí a importância da religião, uma vez que ela constitui "uma reserva de símbolos e significados, reproduzidos institucionalmente, ou livremente buscados pelos indivíduos, dentro de uma multiplicidade de percursos e níveis" (MARTELLI, 1995, p. 453).

Neste mesmo mundo, nesta mesma sociedade fragmentada (HALL, 2006), cheia de opções, ausente de fixação, em que "falta profundidade" (TASCHNER, 2009, p. 34) estão inseridos os profissionais de Serviço Social. Os profissionais que também são seres humanos e buscam constantemente explicações, respostas e caminhos a seguir, tanto na esfera da vida pessoal, quanto a profissional, em face das diversas situações com que lidam. Aqui, a religião vai aparecer para estes profissionais que estão em busca da definição de suas identidades de 
duas formas, na religiosidade, crença e modos de vida dos usuários dos serviços prestados por estes profissionais e na religiosidade do próprio profissional, que se vê em conflito gerado entre os preceitos e ensinamentos da sua religião e do usuário e os preceitos e conflitos que norteiam uma postura ética dados pela profissão.

É com base nesta explanação que destacamos a relação dos temas aqui citados, identidade, modernidade, religião e Serviço Social; e é sob este panorama que demonstramos a importância desta discussão também para a categoria dos Assistentes Sociais, tanto na academia, na formação, quanto no cotidiano do exercício profissional.

\section{Identidade cultural na pós-modernidade e sua presença na religiosidade dos Assistentes Sociais}

Como dissemos, o sujeito portador de identidade única, fixa e estável, vem dando lugar a um sujeito que podemos chamar de fragmentado. Um sujeito que é formado não apenas por uma identidade, mas que se identifica e forma sua própria identidade por meio de várias outras. E essas outras identidades não necessariamente completam esse sujeito ou são completas e claras em si mesmas. Como já abordado em artigo anterior, a constituição da identidade está diretamente vinculada aos grupos e segmentos com os quais as pessoas estão em constante interação, e mesmo em contato com grupos diferentes ou antagôncos (SILVA, 2015, p. 04).

Esse sujeito que possui uma identidade que não é fixa e permanente é chamado de "sujeito pós-moderno" (HALL, 2006), cujo processo identitário é construído histórica e socialmente.

De acordo com Stuart Hall (2006), a identidade fixa é fantasiosa. A segurança, completude e rigidez ofertados pela identidade não existem, são possíveis apenas de forma fantasiosa. A realidade, segundo o autor citado, se refere a um movimento de multiplicação de sistemas de significados que vão confrontando o ser humano com uma gama de identidades possíveis que o leva ao dispêndio de energia para pensar e se identificar. E essa identificação não precisa ser para sempre, porque podemos nos identificar temporariamente com algo ou alguém (HALL, 2006).

A citada "crise de identidade" se daria, conforme Hall (2006), graças a ausência de uma estabilidade em relação a si mesmo e em relação ao que vivemos em sociedade, ou seja, uma movimentação do lugar e de si. Especificamente, o autor explica que o que ocorreria é um 
"deslocamento" - o deslocamento do centro e sua substituição por uma "pluralidade de centros de poder" (HALL, 2006, p.6). Portanto, conforme o pesquisador "Esse duplo deslocamento descentração dos indivíduos tanto no seu lugar no mundo, quanto de si mesmos - constitui uma “crise de identidade” para o indivíduo" (HALL, 2006, p. 9).

Se como dissemos anteriormente, a identidade é algo que se constrói, isso implica compreender que as identidades se constituem enquanto manancial de significados para o sujeito que está neste permanente processo de construção identitária, uma vez que afirmamos que a identificação pode ser temporária. Este processo pode ter origem de forma tanto individual e/ou origem nas instituições sociais que exercem papel dominante; neste caso, o sujeito interioriza as identidades advindas destas instituições. É necessário compreender que o indivíduo é capaz de fornecer o seu próprio significado para as identidades advindas das instituições.

Sobre o descentramento, Hall (2006) nos ensina que na segunda metade do século XX, o que podemos reconhecer por modernidade tardia, avanços na teoria social e nas ciências humanas no campo do pensamento resultaram justamente no descentramento do sujeito racional, metódico e rigoroso. Aquele sujeito característico do iluminismo, cuja identidade, sabemos, era fixa e estável, fora descentrado, dando lugar a uma identidade, a um sujeito mais aberto, identidades não acabadas, fragmentadas, ao que podemos denominar de sujeito pósmoderno. Nas palavras do próprio autor: "[...] as velhas identidades, que por tanto tempo estabilizaram o mundo social, estão em declínio, fazendo surgir novas identidades e fragmentando o indivíduo moderno, até aqui visto como um sujeito unificado" (HALL, 2006, p. 7).

Importante aspecto no desenrolar da modernidade tardia refere-se ao seu constante caráter de mudança. As sociedades modernas diferem-se essencialmente das tradicionais pela característica de constante, rápida e permanente mudança. Sobre a modernidade e sua característica, Marx e Engels destacaram que a burguesia para existir necessita transformar de forma incessante os instrumentos de produção e por consequência, as relações de produção e, portanto, todas as relações sociais:

Dissolvem-se todas as relações sociais antigas e cristalizadas, com seu cortejo de concepções e ideias secularmente veneradas; as relações que as substituem tornam-se antiquadas antes de se consolidarem. Tudo que era sólido e estável se desmancha no ar, tudo que era sagrado é profano e os homens são obrigados finalmente a encarar sem ilusões a sua posição social e as suas relações com 
os outros homens. (MARX e ENGELS, 2005, p.43).

Nesta constante e incessante mudança também se encontram as religiões, não obstante sua resistência à adaptação ao novo, ao diferente.

A religião historicamente ofereceu símbolos de identidade, referências a grupos e comunidades, normas, regras e costumes que impunham um estilo de vida determinado. Com valores, crenças e uma forma particular e definida em enxergar o mundo e de viver em realidade. Por isso é possível afirmar que a religião cumpriu papel fundamental na definição da identidade tanto de pessoas, quanto de grupos.

Martelli (1995) nos explica que anseios por respostas no tempo presente e também no futuro fazem parte da vida das pessoas, o que significa um anseio por sentido, para isso uma das respostas da Igreja são os símbolos, carregados de significados para dar esse sentido à vida das pessoas. No contexto social "pós-moderno", o significado destes símbolos entra em crise, requerendo uma estrutura organizativa. A tradição é um dos principais elementos que sofre o impacto da globalização, que por sua vez atinge diretamente esta suposta estabilidade religiosa.

A tradição, aqui podemos nos deter à religiosa, não derreteu e foi pelo ralo, o que ocorreu é que já não se trata de um elemento incontestável, que se mantinha e fortalecia por gerações. Os impactos desta globalização sacodem as bases tradicionais que passam a ser questionadas e postas à prova, sendo colocadas face a face com uma reflexão que se requer crítica.

Martelli (1995, p.297) indica que a religião na sociedade industrial avançada pode ser explicada pelo cumprimento de sua "função evidente", ou seja, a graça da salvação " que continua sendo pedida, justamente porque é impossível para o sistema social responder com procedimentos racionais (instrumentais) àquilo que, por sua natureza, lhe escapa".

Neste sentido, podemos observar na atualidade uma infinitude de ofertas de igrejas para serem escolhidas - o sujeito pode analisar e escolher aquela com a qual se identifica, e como as identidades podem ser temporárias, a qualquer momento o sujeito pode buscar outra forma de identificação, o que não significa dizer que escolher - consciente ou não - e/ou mudar de instituição religiosa seja o mesmo que trocar ou mudar de identidade, mas que a vivência e a própria análise do sujeito podem indicar-lhe que determinada instituição já não responde aos seus anseios.

De acordo com Follmann (2006), vive-se em uma cultura de decantação da consciência e de afirmação do sujeito em conflito com uma cultura individualista e de massificação, em 
uma conjuntura de desigualdades sociais e econômicas:

Trata-se de um terreno tremendamente propício à multiplicação de buscas de soluções ou, então, à adesão desesperada a fórmulas individuais ou coletivas de fuga e absenteísmos ou de violência e agressividades. O Brasil tem uma vocação histórica à diversidade e ao convívio com o diferente. Essa vocação desemboca, hoje, no referido contexto cultural amplamente propício, ajudando a acelerar, de modo particular, a multiplicação e a diversificação religiosa (FOLLMANN, 2006, p. 27).

Assim, talvez seja possível compreender que a falta de estabilidade do qual estamos falando, assim como a dificuldade de estabelecer padrões e identidades e referências críticas, em virtude da gama de opções, provoque justamente uma conduta de retorno e busca às bases tradicionais e fixas que representavam a estabilidade e a constância. Contudo, o problema aqui, talvez não o único, resida na ausência de crítica.

Esse movimento e alteração no cenário religioso, isto é, nas bases tradicionais da religião, ressignificou seus sentidos e trouxe um aspecto de maior individualização em detrimento de uma institucionalização. $\mathrm{O}$ sujeito religioso tem buscado refletir sobre os aspectos de sua vida e tal fato proporciona um conflito permanente, uma vez que a fé significa crer sem questionar, a estabilidade se esvai com os questionamentos, porque o sujeito tem diante de seus olhos inúmeras possibilidades.

O que se vê aqui é uma maneira de lidar com a religião que privilegia fatores individuais no processo de construção da identidade religiosa e a inserção de questionamentos e reflexão crítica aos elementos religiosos e não mais uma fé, crença, vivência e identificação baseados na tradição unicamente.

No campo do Serviço Social, pesquisas que vêm sendo realizadas, particularmente no Departamento de Serviço Social da Universidade Estadual de Londrina ${ }^{4}$, verificaram que não raro os profissionais se socorrem de sua fé para enfrentar as dificuldades do cotidiano profissional $^{5}$.

É possível verificar cotidianamente na arena social a disputa de tratamentos e posicionamentos em relação a importantes temáticas da vida em sociedade nas esferas política, econômica e social. Algumas pesquisas demonstram que historicamente as religiões têm

\footnotetext{
${ }^{4}$ https://www.sistemasweb.uel.br/system/prj/pes/pdf/pes_pesquisa 09296.pdf

${ }_{5}^{5}$ Para maior aprofundamento, sugerimos ler file://CC:/Users/silva/Documents/2016/Artigo/Artigos\%20publicados\%20em\%202016/Artigo\%20completo\%20S oc\%20em\%20Debate.pdf
} 
ocupado papel de destaque nesta disputa, influenciando opiniões, ações e demarcando suas convicções inclusive na elaboração e execução de políticas sociais e públicas e no aparato jurídico legal que organiza e normatiza a vida em sociedade. Conforme Follmann (2006, p.12):

A afirmação da razão moderna e os avanços da ciência e da tecnologia não conseguiram banir a dimensão religiosa da história humana, e a religião, que sempre marcou presença, continua pontuando em diversas expressões da vida humana, inclusive na disposição do habitat e da indumentária, dos costumes alimentares e outros, e, principalmente, a celebração dos principais momentos da vida (FOLMANN, 2006, p. 12).

Portanto, as pessoas que vivem em sociedade estão dentro dessa arena, assim como os Assistentes Sociais, ou seja, não há como se alienar. Em alguns anos de pesquisa sobre a temática referente à religião e o Serviço Social foi possível verificar que significativa parcela de Assistentes Sociais possui valores e princípios religiosos que exercem em alguma medida influência durante seu exercício profissional, conforme é possível observar:

Perguntamos aos profissionais entrevistados se eles relacionavam os problemas sociais com que lidavam no cotidiano com a espiritualidade [...]. É possível verificar que o profissional atribui a "culpa" dos casos de violência que trabalha no seu cotidiano ao fato de as famílias não terem uma prática religiosa. Passando a ideia de que não adianta o trabalho na instituição, ou seja, o trabalho na política social que atende essas situações se "não seguem a Deus". (DUTRA, 2012, p.73).

Além disso, salienta-se a relação entre convicções religiosas e trabalho profissional, resultado de pesquisa para trabalho de conclusão de curso da autora sob orientação da co-autora, conforme se segue:

[...] observamos a declaração do profissional que afirma que as expressões da questão social, as mazelas resultantes da relação entre capital e trabalho configuram uma espécie de consentimento da parte de Deus para que a humanidade perceba o plano Dele para a vida de cada um na terra. (DUTRA, 2012, p.73).

É claro que os profissionais de Serviço Social não se separam de seus valores e convicções durante o período de trabalho, tais valores, opiniões e convicções foram formadas ao longo da vida deste profissional dentro dos grupos sociais em que esteve inserido, grupos como a escola, a família e a igreja, em transversalidade com as questões de classe, raça, etnia, gênero, sexualidade, entre outras. 
De acordo com pesquisa realizada para dissertação de mestrado da autora, em que profissionais de serviço social foram entrevistados:

Todas as entrevistadas afirmaram possuir um vínculo religioso de família anterior ao processo de formação profissional [...] as profissionais apresentam como motivação para a escolha da carreira a ideia de "ajuda ao próximo". "A gente não tinha muitas vezes o que fazer. Na verdade, era muitas vezes destituir e colocar o joelho no chão e pedir uma família que viesse e quisesse aquela criança para chamar de sua da forma como ela precisava [ENTREVISTA, 2017]". A profissional espera, não nas condições objetivas sobre o caso que se debruça profissionalmente, mas em um ser superior, externo (DUTRA, 2017, p.73).

Follmann (2006, p. 13) nos ajuda a compreender que é possível adequar convicção religiosa à vida moderna, já que ela é mobilizada para proporcionar esperança e conforto em situações de desespero:

Ela oferece trabalho beneficente, é de fonte de inspiração artística e, para muitos, constitui um centro de referência social. Se, por um lado, muitos conflitos religiosos mundiais têm causado dor e morte, por outro lado, a religião também é a base para os mais diversos movimentos de apoio e luta pela paz.

Algumas investigações científicas, como por exemplo, Quintão (2012); Santana (2010); Silva, Dutra, et. al. (2016); Souza (2016); Simões Neto (2015); Kobayasi (2012); Dutra (2012); Dutra (2017), revelaram que não raro os profissionais de Serviço Social se fundamentam em seus valores religiosos no exercício profissional com a finalidade de dar respostas às expressões da "questão social" com que lidam, colocando tais valores e convicções como um instrumento profissional que julgam ser capaz de dar as respostas que os instrumentos técnicos disponíveis e o conhecimento adquirido na formação profissional não estariam sendo capazes de dar, ao menos naquele momento.

As convicções religiosas também são utilizadas pelos profissionais no auxílio à análise e posicionamento de matérias que carregam polêmica e controvérsia, como por exemplo, a descriminalização do aborto, redução da maioridade penal, eutanásia, questões ligadas aos direitos da população LGBT, raça e etnia, violência contra a mulher, entre tantas outras.

Por isso, indicamos que dentro desta categoria profissional encontra-se uma parcela de profissionais que exerce sua profissão também à luz de valores e princípios religiosos em 
detrimento do aparato teórico-metodológico, ético-político e técnico-operativo. Podemos afirmar que:

[...] ficou evidente que o aparato profissional oriundo da formação em Serviço Social, assim como os instrumentos e técnicas, que conformam a prática profissional, sugere ser insuficientes para o enfrentamento das questões que se mostram no cotidiano institucional. Apresentou-se a necessidade de uma crença em alguma coisa, alguém, talvez não com o nome e a cara de Jesus Cristo, ou de qualquer outro deus, mas algo que possua uma dimensão e o poder que a humanidade e os aparatos humanos e sociais não oferecem. (SILVA e DUTRA, et. al. 2016, p. 432).

A dissertação de mestrado da autora mostrou que, entre outras coisas, a religião e a religiosidade estavam postas como elementos de formação e desenvolvimento dos homens, elementos postos como constitutivos da vida em sociedade. Os dados obtidos com a pesquisa empírica deram conta de revelar que o cotidiano profissional com todas as suas contradições traz aos profissionais um sentimento de carência que eles buscam suprir na religião; buscam na fé em algo ou alguém superior respostas às mazelas com as quais lidam cotidianamente. A religião ainda apareceu como um importante elemento na decisão da escolha do curso de Serviço Social, reafirmando a imagem social da caridade e este é um dado que merece ser melhor estudado e aprofundado com pesquisas acadêmicas.

Alguns importantes títulos foram encontrados, tais como o livro de José Pedro Simões Neto (2005) "Assistentes Sociais e Religião: um estudo Brasil / Inglaterra"; sua pesquisa traz uma análise sobre a política de assistência social no Brasil e, para além disso, problematiza a questão da religião no interior desta categoria profissional, uma vez que identifica seus agentes profissionais encarando como uma missão. O pesquisador demonstra, como temos visto desde que iniciamos a pesquisa sobre temática, que o desejo da ajuda ao próximo, declarada por grande maioria dos profissionais sujeitos da sua pesquisa (assim como da nossa), faz com que a mobilização de valores seja muito maior do que a de conhecimentos técnicos por parte dos profissionais de Serviço Social. O autor aponta que a presença de valores e princípios religiosos no Serviço Social é componente importante em seu interior e é o ponto central de sua pesquisa, sendo desafio estender as perspectivas de análise e construir novas metodologias:

O que se quer defender é o argumento de que os vínculos existentes entre a religião e o Serviço Social se estabeleceram desde suas origens, não só no Brasil, mas também no mundo, e que eles têm acompanhado o fazer profissional ao longo de todos os anos de sua existência. As modificações curriculares, a presença de teorias com supostos materialistas, como o 
marxismo e o positivismo, a presença ou ausência de técnicas interventivas, não afetaram, substantivamente, os vínculos existentes. (NETO, 2005, p. 199).

Outro título importante sobre o assunto é a obra de Luci Faria Pinheiro (2010) "Serviço Social, religião e movimentos sociais, em que a pesquisadora destaca que as transformações da sociedade brasileira, estimulada por uma geração que buscou romper com os valores tradicionais, muitas das quais oriundas da militância religiosa, única possibilidade para as mulheres se manifestarem:

\begin{abstract}
A questão da religião, que deixa registrada a utopia por um mundo mais igual, não é debatida, mas nem por isso foi ultrapassada ou se tornou antiquada ao serviço social. Falta-lhe utilizar suas reservas acumuladas nesse projeto de ruptura para tentar desvendar os novos arranjos da religião, sem mais se ater simplesmente à história de seu conservadorismo, história essa que não foi conduzida somente pela presença forte da Igreja, mas sobretudo pelo viés da classe (PINHEIRO, 2010, p. 69).
\end{abstract}

Foi possível encontrar também alguns artigos, como "A relação entre manifestações religiosas e o exercício profissional dos assistentes sociais: um estudo das contradições e possibilidades no norte do Paraná" (SILVA, DUTRA, et. al. 2016). Encontramos ainda dois artigos que analisaram a temática da religião entre alunos dos cursos de Serviço Social em Universidades Públicas, um deles é de Pedro Simões Neto (2007) "Religião e Política entre alunos de Serviço Social (UFRJ)"; outro de Tiemi Mori, resultado de seu trabalho de conclusão de curso de graduação na UEL, artigo publicado em 2016 juntamente com a professora Claudia Neves da Silva. Uma dissertação de mestrado, de autoria de Graziela Ferreira Quintão (2012), intitulada "A questão da Religião no Trabalho do Assistente Social. Fragmentos da realidade na Região dos Lagos, Rio de Janeiro", também foi encontrada. Outros dois trabalhos de conclusão de curso defendidos na UEL trataram da temática religiosa entre Assistentes Sociais e estudantes, um de autoria de Susana Kobayasi (2012) "Religião e Serviço Social: As manifestações religiosas dos estudantes no cotidiano da sala de aula" e outro de autoria de Regiane Souza (2016): “A Presença da Religião e de Valores e Princípios Religiosos no Exercício Profissional do Assistente Social”. Há também o trabalho de conclusão de curso de graduação de Juliana Aguiar Santana (2010) “Assistentes sociais e religião: um estudo sobre os impactos da religiosidade no exercício profissional do assistente social na contemporaneidade". 
O artigo de Paulo Wescley Maria Pinheiro (2015) "Serviço Social, neoconservadorismo religioso e o desafio para a formação profissional", resultado de sua dissertação de mestrado, indica, entre outras coisas, a tensão entre valores religiosos e conteúdo do curso, pois verificase o conflito de valores provocado pelo ambiente acadêmico:

Nesse processo, não demora muito para que as questões dos valores religiosos se evidenciem e, com elas, as queixas e reivindicações, tanto por uma suposta imposição do modo de pensar na profissão, como também por compreenderem que o ambiente de formação profissional é desfavorável para os debates sob o prisma religioso. (PINHEIRO, 2015, p. 2012).

Não obstante a dificuldade e por vezes a recusa para debater o tema religião e religiosidade no interior na universidade, ocasionando a dificuldade de encontrar materiais sobre o tema, particularmente do curso de Serviço Social, é importante destacar que já é possível verificar um movimento do conjunto formado pelo Conselho Federal de Serviço Social e Conselhos Regionais de Serviço Social para tratar o tema em oficinas e publicações próprias, como o "CFESS Manifesta", que na primeira edição do ano de 2016 levou o título de "CFESS se manifesta: Estado laico já".

\section{CONCLUSÃO}

É possível compreender que a sociedade passou e passa por um processo de globalização cujos resultados incidem diretamente no processo de identificação e/ou construção da identidade dos sujeitos na modernidade tardia, criando assim uma crise de identidade no sujeito pós-moderno.

A sociedade em que vivemos parece ter se tornado um lugar pequeno, isso não se deve a ausência de espaço ou de recursos. A sociedade parece não ter suficiente espaço em relação às formas que os indivíduos criaram e vem criando como tentativa de organização para a vida. As indagações cotidianas causam, em nosso tempo e sociedade, um misto de busca por respostas que levam as pessoas a fazerem inúmeras indagações e ao mesmo tempo buscar um lugar compassivo.

Vimos que este processo, que atingiu diretamente elementos como a tradição e o campo religioso, nutrem um permanente conflito na vida em sociedade. Os profissionais de Serviço Social, por sua vez, não estão alheios a este processo e temos demonstrado com pesquisas que eles vivem um conflito ao questionarem e refletirem sobre sua fé e identidade religiosa ao 
mesmo tempo em que precisam dar respostas às exigências éticas profissionais em seu cotidiano de trabalho, permeado por demandas que dividem opinião; verificamos também que a religião faz parte da construção da identidade do sujeito profissional.

Mesmo na vida moderna, a religião é requerida como uma fonte de esperança e conforto para a vida, porque oferece motivo e sentido, inspira e se coloca, na maior parte dos casos, para muitas pessoas, como um centro de referência social.

Por isso é possível afirmar a urgência e importância da proposta deste debate no âmbito do Serviço Social. Este âmbito contempla estudantes em todos os níveis de formação, estudantes que se dedicam a pesquisa, docentes e profissionais em exercício ou não. As questões que se relacionam ao exercício profissional atrelado com a temática da religião são necessárias dentro dos espaços de formação profissional dos Assistentes Sociais.

\section{REFERÊNCIAS}

DUTRA, Patrícia Vicente. Manifestações sociorreligiosas dos assistentes sociais e suas repercussões imediatas nas práticas laborais do tempo presente ao Oeste do Paraná. 2017. 80 f. Dissertação (Mestrado em Serviço Social) - Universidade Estadual do Oeste do Paraná, Toledo, 2017.

DUTRA, Patrícia Vicente. Religião, Religiosidade e Serviço Social: um estudo sobre a presença da religião e da religiosidade na prática profissional do Serviço Social na atualidade. 2012. 94f. Trabalho de Conclusão de Curso (Graduação em Serviço Social) - Universidade Estadual de Londrina: Londrina, 2012.

FOLLMANN, José Ivo. O mundo das religiões e religiosidades: alguns números e apontamentos para uma reflexão sobre novos desafios. In: SCARLATELLI, Cleide Cristina da Silva. STRECK, Danilo Romeu. FOLLMANN, José Ivo. (orgs). Religião, Cultura e educação. São Leopoldo: Editora Unisinos, 2006.

HALL, Stuart. A identidade cultural na pós-modernidade. Rio de Janeiro. DP\&A, 20062011.

KOBAYASI, Susana. Religião e Serviço Social: As manifestações religiosas dos estudantes no cotidiano da sala de aula. Londrina. 2012.

ARTELLI, Stefano. A religião na sociedade pós-moderna: entre a secularização e a dessecularização. São Paulo: Paulinas, 1995.

MARX, Karl e ENGELS, Friedrich. Manifesto Comunista. Tradução de Álvaro Pina. São Paulo: Boitempo Editorial, 2005. 
PINHEIRO, Lucí Faria. Serviço social, religião e movimentos sociais no Brasil. Rio de Janeiro: FAPERJ Gramma, 2010.

PINHEIRO, Paulo Wescley Maia. Serviço Social, neoconservadorismo religioso e o desafio para a formação profissional. Temporalis, Brasília (DF), ano 15, n. 29, jan. /jun. 2015.

QUINTÃO, Graziela Ferreira. A questão religiosa no trabalho do assistente social: fragmentos de uma investigação na atualidade. 2012. Dissertação de mestrado (mestrado em política social) Universidade Federal Fluminense, Niterói, RJ, 2012.

SANTANA, Juliana Aguiar. Assistentes sociais e religião: um estudo sobre os impactos da religiosidade no exercício profissional do assistente social na contemporaneidade. 2010. Trabalho de Conclusão de Curso (Graduação em Serviço Social) Universidade Federal Fluminense, Campos dos Goytacazes, 2010.

SCARLATELLI, Cleide Cristina da Silva. STRECK, Danilo Romeu. FOLLMANN, José Ivo. (orgs). Religião, Cultura e educação. São Leopoldo: Editora Unisinos, 2006.

SILVA, Claudia Neves. Manifestações religiosas de jovens na contemporaneidade: experiências pentecostais cotidianas. XXVIII Simpósio Nacional de História. Florianópolis: 27-31/julho/2015. (p.1-11)

SILVA, Claudia Neves. DUTRA, Patrícia Vicente. LANZA, Fábio. A relação entre manifestações religiosas e o exercício profissional dos assistentes sociais: um estudo das contradições e possibilidades no norte do Paraná. Revista Sociedade em Debate. v. 22. n. 2. Dezembro de 2016. Disponível em: http://revistas.ucpel.tche.br/index.php/rsd/article/view/1420/944.

SIMÕES NETO, José Pedro. Assistentes sociais e religião: um estudo Brasil/Inglaterra. São Paulo: Cortez, 2005.

TASCHNER, G. Cultura, consumo e cidadania. EDUSC: Bauru, 2009. 